\title{
Endoscopic ultrasound-guided ablation of pancreatic cystic neoplasms: ready for prime time?
}

\author{
Andrew Ofosu ${ }^{a}$, Daryl Ramai ${ }^{b}$, Douglas G. Adler \\ The Brooklyn Hospital Center, NY; University of Utah School of Medicine Huntsman Cancer Center, Salt Lake City, \\ Utah, USA
}

\begin{abstract}
With the increase in the use of cross-sectional diagnostic imaging, there has been a concomitant rise in the rate of detected pancreatic cystic lesions. Recent years have seen the rise of newly developed therapeutic modalities to treat pancreatic lesions via ablation. Specifically, through the use of endoscopic ultrasound-guided therapy, endoscopists can potentially ablate these lesions safely and with minimally invasive techniques. In this manuscript we review 4 major endoscopic ultrasound-guided ablative therapies: radiofrequency ablation, ethanol injection, chemo ablation, and cryoablation. We also review the efficacy and safety of these techniques and future directions in the management of cystic pancreatic lesions.
\end{abstract}

Keywords Endoscopic ultrasound, pancreatic neoplasm ablation, ethanol ablation, radiofrequency ablation

Ann Gastroenterol 2019; 32 (1): 1-7

\section{Introduction}

Cystic lesions of the pancreas can be subclassified into noninflammatory fluid collections or non-neoplastic pancreatic cysts, pancreatic cystic neoplasms (PCNs), inflammatory fluid collections such as acute fluid collections, and pancreatic pseudocysts (not lined by epithelium). Inflammatory fluid collections are benign with no malignant potential. There are 4 major types of PCNs: serous cystic adenomas (SCAs), mucinous cystic neoplasms (MCNs), intraductal papillary mucinous neoplasms (IPMNs), and solid pseudopapillary neoplasms (SPPNs) [1].

PCNs may have negligible malignant potential (SCAs) or may represent premalignant lesions (particularly IPMNs or MCNs) or malignant tumors (invasive IPMNs or mucinous cystadenocarcinomas). The destruction of the epithelial lining

aDivision of Gastroenterology and Hepatology (Andrew Ofosu);

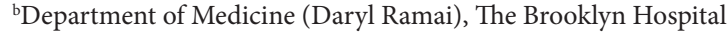
Center, Brooklyn, New York; ' Division of Gastroenterology and Hepatology, University of Utah School of Medicine, Huntsman Cancer Center, Salt Lake City, Utah (Douglas G. Adler), USA

\section{Conflict of Interest: None}

Correspondence to: Douglas G. Adler MD, FACG, AGAF, FASGE, Division of Gastroenterology and Hepatology, University of Utah School of Medicine, Huntsman Cancer Center. Salt Lake City, Utah, USA, e-mail: Douglas.adler@hsc.utah.edu

Received 12 September 2018; accepted 2 November 2018; published online 3 December 2018

DOI: https://doi.org/10.20524/aog.2018.0331 of PCNs can potentially eliminate or reduce their malignant potential (Fig. 1,2).

Surgical resection is the definitive treatment for cystic lesions with suspected malignant potential. However, the morbidity and mortality associated with surgical outcomes have been reported to be $30 \%$ and $2.1 \%$, respectively [2]. Alternatively, conservative management of pre-malignant pancreatic lesions requires serial imaging using computed tomography (CT) scan or magnetic resonance imaging (MRI). The survival benefit associated with surveillance of pancreatic cysts is still unproven, given the lack of long-term data and prospective studies designed to determine its mortality benefit [3].

Additionally, pancreatic cyst surveillance is expensive, with a potential to impose a burden on the US healthcare system, particularly if the use of imaging and the concomitant discovery of incidental pancreatic neoplasms continues to grow [4]. Moayyedi et al estimated a median cost of $\$ 9.3$ billion per year if all patients within the 40-79 year age group with a pancreatic cyst had an MRI for surveillance [4].

\section{Endoscopic ultrasound (EUS)-guided ablation}

EUS has evolved as a therapeutic modality in the diagnosis and management of pancreatic diseases. EUS-guided ablation of pancreatic cysts provides a potentially less invasive treatment option in appropriately selected patients, with less morbidity and mortality compared with surgery [5] (Fig. 3). Additionally, pancreatic cyst ablation, if successful, could potentially lengthen 


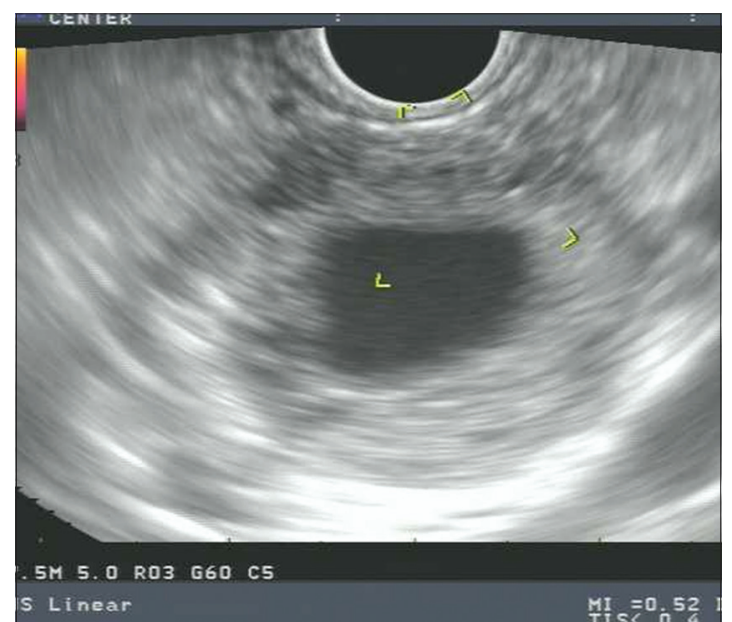

Figure 1 Thick-walled pancreatic pseudocyst. This lesion would not be considered for endoscopic ablation

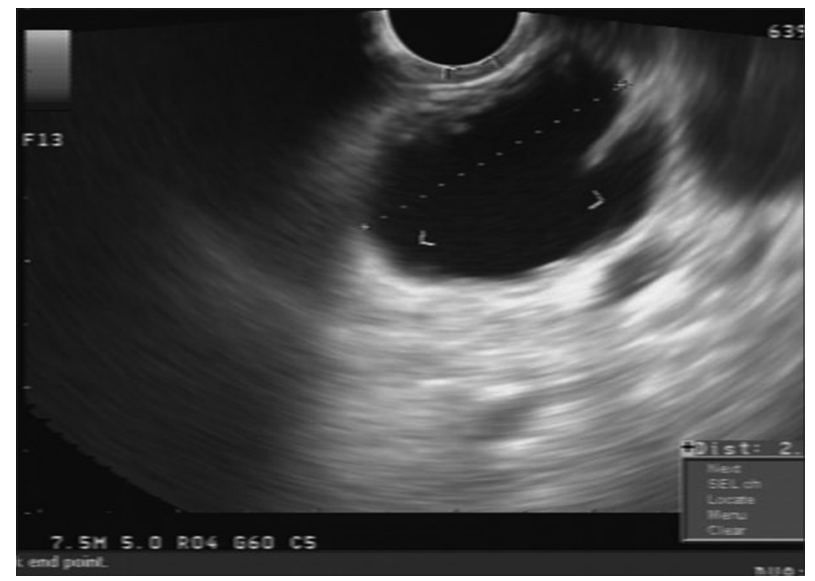

Figure 2 Septated mucinous cystic neoplasm of the pancreas. This lesion could be considered for endoscopic ablation

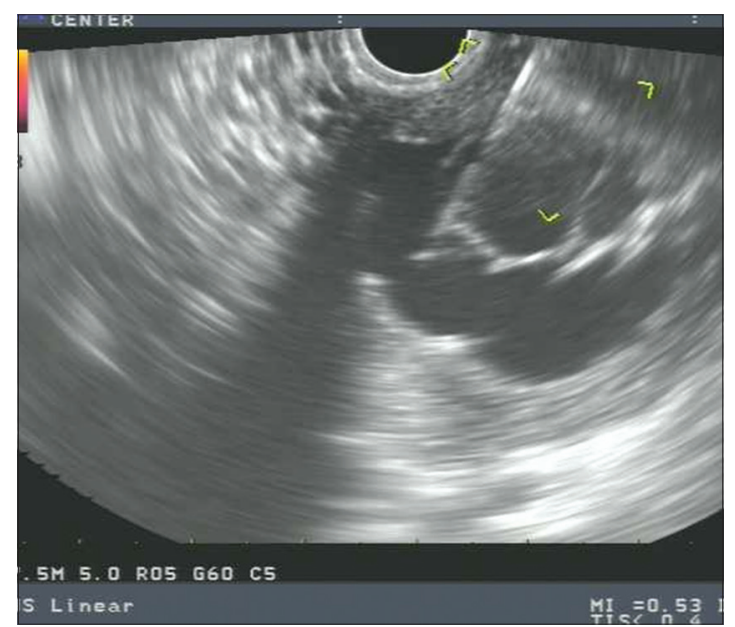

Figure 3 Endoscopic ultrasound fine-needle aspiration needle in a septated mucinous cystic neoplasm of the pancreas. The needle could be used to both aspirate the cyst contents and inject an ablative agent surveillance intervals or reduce the need for periodic surveillance. EUS-guided approaches enable real-time imaging of the pancreatic lesions and would allow endoscopists to approach less accessible cystic lesions.

Potential drawbacks to the use of EUS-guided cyst ablation include adverse events associated with endoscopic ablation, from either the endoscopy or the injection of ablative agents. Some adverse events noted in the literature include pancreatitis, abdominal pain, intra-cystic bleeding and thrombosis of the portal venous system, and rarely splenic vein thrombosis [6]. After ablation, some epithelium may remain untreated and therefore could continue to harbor malignant potential [7]. Patients with IPMNs are at increased risk of pancreatic cancer at a site separate from the cyst and will require ongoing surveillance despite ablation, limiting its role in IPMN.

\section{Ethanol-induced ablation (EA)}

Ethanol is an easily obtainable, low-cost, ablative agent with the potential to induce denaturation of proteins, lysis of cell membranes and vascular occlusion [8]. Ethanol can obliterate the cystic epithelium, which conceivably reduces the likelihood of malignancy [9]. The use of ethanol as an ablative agent has been demonstrated in hepatic neoplastic lesions such as hepatocellular carcinoma (HCC), adrenal tumors, gastric intestinal stromal tumors, and other metastatic lesions [10-12].

Using a transgastric or transduodenal route, an EUS-guided fine-needle aspiration (FNA) needle can be introduced into the cyst. With a syringe attached to the proximal end of the needle, cyst fluid can be aspirated to near-complete evacuation of the cyst. This is typically achieved through the use of a 22-G or 19-G needle. With the needle in the collapsed cyst, ethanol is injected into the cyst in a volume equal to that initially aspirated from the cyst [13]. Cyst lavage is usually performed, alternately filling and emptying the cavity over 3-5 min. Alternatively, ethanol can be left to sit within the cystic cavity and extracted after 3-5 min. After lavage, the ethanol-cyst fluid mixture is drained as completely as possible [13].

Gan et al were the first to demonstrate the success and safety of EUS-guided EA (EUS-EA) of pancreatic cysts. In their study, 25 patients underwent cystic evacuation using a $22-\mathrm{G}$ needle. Lavage of the cyst cavity was performed for 3-5 min using a $5 \%$ ethanol solution. The concentration of ethanol was subsequently increased to a maximum of $80 \%$. Patients were monitored for complications for $2 \mathrm{~h}$ after the procedure, and further follow up was obtained at $72 \mathrm{~h}$ and one year after lavage. Of the 23 patients who achieved one-year follow up, $8(35 \%)$ demonstrated complete resolution on cross-sectional imaging [14].

Likewise, in a multicenter randomized double-blinded study by DeWitt et al, the use of ethanol vs. saline in pancreatic cyst ablation was studied in 42 patients (ethanol, $n=25$; saline solution, $n=17$ ) [15]. Using a 22-G needle, a transgastric or transduodenal puncture of the cyst was performed. With the needle in the nearly collapsed cyst, the lavage agent (saline 
solution or ethanol) was injected into the cyst in a volume equal to that of the fluid initially aspirated. Cross-sectional CT imaging was performed 3-4 months after the last planned cyst lavage to evaluate for resolution (absence of any visible cyst) or change in cyst size.

EUS-EA achieved a greater reduction in cyst surface area compared with saline alone $(-42.9 ; 95 \%$ confidence interval [CI] -58.4 to -27.4 vs. -11.4 ; $95 \% \mathrm{CI},-25.0$ to 2.2 ; $\mathrm{P}=0.009$ ), with CT-defined resolution in $33 \%$ of patients. Histologic analysis of 4 resected cysts showed epithelial ablation from $0 \%$ (with saline solution injection) to $50 \%$ or $100 \%$ (with one or two ethanol lavages, respectively) [15].

Park et al, in a study of 91 patients with clinically indeterminate pancreatic cysts, showed that the success rate of EUS-EA was dependent on the type of pancreatic cyst, based on cyst fluid analysis and cyst size [16]. The results indicated that the initial diameter of pancreatic cystic lesions (PCLs) in the clinical response group was significantly lower compared with the persistent cyst group (median, $27 \mathrm{~mm}$ vs. $30 \mathrm{~mm}$; $\mathrm{P}=0.017$ ). Additionally, IPMN lesions had lower response rates after ablation compared with other PCLs: 58\% in serous cystic neoplasms, 50\% in MCNs, and 11\% in IPMNs.

To determine how many sessions of EUS-EA were needed to achieve cyst resolution, Dimaio et al compared one session of EUS-EA treatment with two or more sessions. In the 13 patients enrolled in their study, results showed that two sessions of EUS-endoscopic lavage resulted in a significant decrease in the size and surface area of PCLs and a significantly higher rate of image-defined cyst resolution [17]. Only one patient had minimal abdominal pain two days after second session. However, the very small sample size did not allow for a detailed analysis of adverse effects.

To evaluate the clinical benefits and survival gain from the use of EUS-guided ethanol ablation, Choi et al conducted a propensity score-matching analysis among 84 matched pairs of EUS-EA for PCLs compared with the natural course (NC) of pancreatic cysts [18]. Their study indicated that overall survival did not differ significantly between the EUS-EA group and the NC group (194.12 vs. 247.54 days, respectively; $\mathrm{P}=0.235$ ). Surgical resection rates were lower in the EUS-EA group than in the NC group.

Despite the favorable outcomes of the above studies, a study by Gomez et al with long-term follow up showed that EUS-EA resulted in complete resolution of cysts in only a small proportion of participants [7]. In their study, among 23 patients who had EUA-EA with follow up over 40 months, only 2 participants had complete resolution of pancreatic cysts. The authors concluded that the injection of contrast medium into cysts before ethanol lavage potentially reduced the effective ethanol concentration. Additionally, the use of contrast-enhanced imaging could have potentially increased the sensitivity for residual cysts [7].

EUS-EA has not been widely adopted, in view of the inherent risk of acute pancreatitis from extravasation of ethanol into either the parenchyma or pancreatic duct and the very limited data, as mentioned above (Table 1). Further techniques, combining chemotherapy such as paclitaxel and ethanol, are currently being evaluated, with the goal of minimizing the use of ethanol to improve the efficacy and safety of pancreatic cyst ablation (Table 1) [19].

\section{Radiofrequency ablation (RFA)}

RFA uses a high-frequency $(460-500 \mathrm{kHz})$ alternating current to deliver targeted therapy, which induces coagulative necrosis of tissue, cell apoptosis, and eventually irreversible cell damage [20]. The use of RFA has been demonstrated as an effective and safe therapeutic modality for managing focal malignant lesions such as HCC, Barrett's esophagus and malignant biliary strictures, most commonly from cholangiocarcinoma [21-23].

RFA is applied through monopolar or bipolar probes. With the monopolar probe, high-current-density energy heats the target tissue through an electrode [24]. In a bipolar RFA system, the current flows between two interstitial electrodes and does not require a grounding pad. Bipolar probes provide an overall minor ablative capacity compared to monopolar probes; however, heat injury is delivered rapidly with less damage to the surrounding healthy tissue [24]. There is also potential immunomodulation with an anti-cancer effect after application of RFA [25].

EUS-guided RFA (EUS-RFA) can potentially be used in the ablation of pancreatic cysts in patients who are not surgical candidates because of existing comorbidities. Gaidhane et al demonstrated the effectiveness and safety of EUS-RFA when applied to the normal porcine pancreas, using 6-mm and $10-\mathrm{mm}$ RFA probes through a $19-\mathrm{G}$ needle in a transduodenal approach [26]. In their study, 5 pigs underwent EUS-RFA of the head of the pancreas. In 3 of the 5 pigs the proximal pancreas showed moderate tissue injury. This was expected given the proximity of the tissue to the procedure site. There was no reported mortality or major complication. Moderate pancreatitis occurred in one pig model and seemed to be associated with procedure time. Three days after the procedure, total bilirubin, alkaline phosphatase, cell blood count and amylase were within normal limits.

Likewise, Silviu et al evaluated the use of EUS-RFA using a $0.33-\mathrm{mm}$ RFA probe through a $19-\mathrm{G}$ EUS-FNA needle in 10 pigs [27]. The aim of the study was to assess the feasibility and safety of EUS-guided RFA of the pancreas. In their study, 4 sessions of consecutive ablations to the head of the pancreas was performed to determine if exposing the pancreatic tissue to consecutive ablative procedures was more effective. The complications observed included iatrogenic gastric wall injury $(n=1)$ and moderate ascites $(n=1)$. The former was most likely due to improper placement of the electrode and long exposure to high current. Histopathology showed areas of coagulative necrosis corresponding to the site of application of the probe. There was no evidence of pancreatitis at sites $2-3 \mathrm{~cm}$ away from the areas of coagulative necrosis. The authors concluded that EUS-guided RFA is effective for ablating pancreatic tumors, though much remains to be addressed in terms of safety.

EUS-guided pancreatic RFA has been evaluated in only a few human case series, mostly in patients with pancreatic 
Table 1 Treatment outcomes and adverse events of endoscopic ultrasound-guided ethanol ablation of pancreatic cysts

\begin{tabular}{|c|c|c|c|c|c|c|c|c|}
\hline Study & Year & $\begin{array}{l}\text { Number } \\
\text { of patients }\end{array}$ & $\begin{array}{c}\text { Mean age } \\
\text { (years) }\end{array}$ & $\begin{array}{c}\text { Mean diameter/ } \\
\text { ablative agent }\end{array}$ & Type of cyst & $\begin{array}{l}\text { Follow up } \\
\text { (months) }\end{array}$ & Adverse events & Cyst resolution (\%) \\
\hline Gan et al [14] & 2005 & 25 & 64.5 & $19.4 \mathrm{~mm} /$ Ethanol & $\begin{array}{l}\text { IPMN } 12 \% \text {, SCA } 12 \% \text {, } \\
\text { PCs } 4 \% \text {, MCN 56\%, } \\
\text { unknown } 8 \%\end{array}$ & $6-12$ & $0 \%$ & $35 \%$ \\
\hline Oh et al [36] & 2008 & 14 & 50 & $\begin{array}{c}25.5 \mathrm{~mm} / \text { Ethanol } \\
\text { and Paclitaxel }\end{array}$ & $\begin{array}{l}\text { SCA } 2 \% \text {, } \\
\text { lymphangioma 21\%, } \\
\text { MCN 14\%, } \\
\text { unknown } 43 \%\end{array}$ & $6-23$ & $\begin{array}{l}\text { Acute pancreatitis } \\
(7 \%)\end{array}$ & $79 \%$ \\
\hline Oh et al [45] & 2009 & 10 & 38.4 & $\begin{array}{c}29.5 \mathrm{~mm} / \text { Ethanol } \\
\text { and paclitaxel }\end{array}$ & $\begin{array}{l}\text { MCN 30\%, SCA 40\%, } \\
\text { unknown } 30 \%\end{array}$ & $\begin{array}{l}29.5 \text { median } \\
20-68\end{array}$ & $\begin{array}{l}\text { Acute pancreatitis } \\
(10 \%)\end{array}$ & $60 \%$ \\
\hline DeWitt et al [15] & 2009 & 42 & 69.1 & $\begin{array}{l}22.4 \mathrm{~mm} / \text { Ethanol } \\
\text { vs. saline }\end{array}$ & $\begin{array}{l}\text { MCN } 40 \% \text {, IPMN } \\
40 \% \text {, SCA } 12 \% \text {, } \\
\text { PCs } 7 \%\end{array}$ & $\begin{array}{c}20.5 \\
(10-40)\end{array}$ & $\begin{array}{l}\text { Acute pancreatitis } \\
(2.4 \%) \text {, intracystic } \\
\text { bleeding }(2.4 \%) \text {, } \\
\text { abdominal pain } \\
(24 \%) \text {, major } \\
\text { complications, } \\
(24 \%)\end{array}$ & $\begin{array}{c}33 \% \text { (ethanol) } \\
0 \% \text { (saline) }\end{array}$ \\
\hline Oh et al [37] & 2011 & 52 & 49.5 & $\begin{array}{c}31.8 \mathrm{~mm} / \text { Ethanol } \\
\text { and paclitaxel }\end{array}$ & $\begin{array}{l}\text { MCN 17\%, SCA } 29 \% \\
\text { PCs } 4 \% \text {, } \\
\text { unknown } 50 \%\end{array}$ & $\begin{array}{c}21.7 \text { mean } \\
(2-44)\end{array}$ & $\begin{array}{l}\text { Fever }(2 \%), \\
\text { acute pancreatitis } \\
(2 \%) \text {, abdominal } \\
\text { pain }(2 \%), \text { splenic } \\
\text { vein obliteration } \\
(2 \%)\end{array}$ & $62 \%$ \\
\hline DiMaio et al [17] & 2011 & 13 & 70 & $20.1 \mathrm{~mm} /$ Ethanol & IPMN-100\% & $\begin{array}{l}3-6 \text { after } 2^{\text {nd }} \\
\text { lavage }\end{array}$ & $\begin{array}{l}\text { Abdominal pain } \\
(15 \%)\end{array}$ & $38 \%$ \\
\hline Park et al [16] & 2016 & 91 & 58 & $30 \mathrm{~mm} /$ Ethanol & Indeterminate & $\begin{array}{c}40 \text { median } \\
(13-117)\end{array}$ & $\begin{array}{l}\text { Fever }(9 \%) \text {, } \\
\text { abdominal pain } \\
(20 \%) \text {, acute } \\
\text { pancreatitis }(3 \%)\end{array}$ & $45 \%$ \\
\hline Moyer et al [19] & 2016 & 10 & 71.6 & $\begin{array}{c}30 \mathrm{~mm} / \text { Ethanol } \\
\text { or saline followed } \\
\text { by paclitaxel and } \\
\text { gemcitabine }\end{array}$ & $\begin{array}{l}\text { MCN 70\%, } \\
\text { IPMN 30\%, } \\
\text { unknown 10\% }\end{array}$ & 12 & $\begin{array}{l}\text { Acute pancreatitis } \\
(10 \%)\end{array}$ & $\begin{array}{l}75 \% \text { (ethanol plus } \\
\text { paclitaxel and } \\
\text { gemcitabine) } 67 \% \\
\text { (alcohol-free arm) }\end{array}$ \\
\hline
\end{tabular}

IPMN, intraductal papillary mucinous neoplasm; PC, pseudocyst; $M C N$, mucinous cystic neoplasm; SCA, serous cystadenoma

cancer or pancreatic neuroendocrine tumors, with few studies involving PCLs $[28,29]$. Pai et al conducted a multicenter study to determine the safety and efficacy of EUS-RFA in 6 patients with cystic pancreatic lesions (4 MCNs, 1 IPMN, and 1 microcystic adenoma) [30]. Technical success was achieved in all cases, with complete resolution in $33 \%(n=2)$ of patients, and a $50 \%$ size reduction in $50 \%(n=3)$. As in the porcine models there were no major complications. Two patients, however, developed mild, self-limiting abdominal pain [30].

Some potential adverse effects associated with RFA include thermal injury to the bile duct, which can lead to biliary leakage, pancreatic parenchyma injury, ascites, gastric injury and vascular injury $[27,31,32]$. Additionally, some limitations of RFA have been described. RFA leads to a heat-sink effect, which has been described as a phenomenon that occurs when heat is absorbed by blood in an adjacent vessel. This releases heat and limits the effectiveness of RFA treatment [33].

Overall, the data regarding the application of RFA for pancreatic cyst ablation are encouraging but very limited, with only a few human case series and animal data. An ongoing Phase II multicenter trial of EUS-RFA is being conducted to evaluate the outcomes of pancreatic cyst at 12 months following cyst RFA [34]. Further large prospective and controlled human studies with long follow up are also needed to establish the efficacy and safety of the use of EUS-RFA in the management of cystic pancreatic lesions.

\section{Chemotherapy-chemoablation combined with ethanol}

Paclitaxel is a chemotherapeutic agent that is viscous and hydrophobic and is thought to be potentially less likely to leak from a puncture site. These characteristics enable paclitaxel to induce a long-term effect within a closed cystic cavity, with fewer complications [35]. With the aim of developing more effective treatment modalities or ablation agents to improve treatment responses, Oh et al evaluated the synergistic effect of alcohol and paclitaxel [36]. The technique involved ethanol lavage followed by injection of paclitaxel as a treatment modality for PCLs. As paclitaxel can be dissolved in ethanol, it was reasonably hypothesized that the ethanol would distort the 
lining of the epithelium while the paclitaxel exerted additional apoptotic effects [36].

In their study, 14 patients underwent EUS-guided ethanol lavage with paclitaxel injection (EUS-EP) with a mean follow up of 9 months. Complete resolution of cystic tumors was observed in 11 patients, with partial resolution in 2 patients, and cyst persistence in 1 patient. One patient developed acute pancreatitis with minor complications including vague abdominal pain. EUS-EP was shown to be a safe and effective method for treating cystic tumors of the pancreas [36].

In a subsequent larger study, also by $\mathrm{Oh}$ et al, the inhibitory effects of ethanol and paclitaxel were studied in 52 patients over a long-term follow up of more than 1 year [37]. Complete cyst resolution occurred in 29 patients, while a partial response was observed in 6 patients and persistent cysts in 12 patients. Multivariate analysis showed that the original cyst volume was a major predictor for cyst resolution. Acute pancreatitis was observed in 1 patient and others had minor complications, including hyperamylasemia $(n=6)$ and vague abdominal pain $(n=1)$. While these two studies demonstrated a significant treatment response, they were both limited by small sample sizes.

With the aim of improving on the safety and efficacy of EUS-guided cyst ablation, Moyer et al evaluated the use of chemotherapy (paclitaxel/gemcitabine), with or without prior ethanol lavage, for the ablation of pancreatic MCNs [38]. They reasonably hypothesized that using a multiagent chemotherapeutic regimen and eliminating alcohol would decrease adverse events while potentially increasing the rate of complete cyst resolution.

In the Chemotherapy for Ablation and Resolution of Mucinous pancreatic cysts (CHARM) trial, patients in the control arm had ethanol lavage of the cyst, followed by injection of paclitaxel/gemcitabine. Patients in the study arm received normal saline lavage followed by injection of the same chemotherapy [38]. The results from this study indicated that the ablation rates at 12 months post-treatment were similar for the alcohol lavage group and the alcohol-free arm (61\% vs. 67\%). This study, however, had some notable limitations, including a small sample size and limited doses of chemotherapeutic agents, well below their maximum toxic doses. Despite similar ablation rates, serious adverse events $(6 \%)$ and minor adverse events (22\%) were higher in the control group vs. the alcohol-free group [38]. The study concluded that ethanol might not be a required agent when chemotherapy is used for cyst ablation and its exclusion from treatment could potentially reduce ethanol-related adverse effects. Further large multicenter studies with long-term follow up are needed to determine the efficacy and safety of these techniques.

\section{Cryothermal ablation}

Cryothermal ablation of pancreatic cysts involves the application of a hybrid bipolar probe that combines the thermal energy of RFA with a cryogenic gas, which provides a cooling effect [5]. Cryogenic gases induce cell injury through the application of nitrogen, argon or carbon dioxide gas, typically at a temperature below $-4^{\circ} \mathrm{C}$. Cryothermal ablation utilizes carbon dioxide at $650 \mathrm{psi}$ with a procedure time ranging from 120 to $900 \mathrm{sec}$ [5].

The hybrid bipolar cryothermal probe was developed to enhance the ablative capacity of the bipolar RFA probe [39]. Hines-Peralta et al, in an animal model study using ex vivo livers, demonstrated that larger areas of coagulation were achieved with the simultaneous application of RFA/cryoablation than with each modality alone [40]. Desiccation of tissue by RFA is enhanced by the cooling effect of the cryogenic gas.

Carrara et al investigated the efficacy and safety of bipolar ablation with the use of RFA and cryotechnology of the pancreas in a live pig model [41]. In this study, selective transluminal ablation was achieved and the extent of ablation was correlated with the duration of application. Minor complications were reported, including pancreatitis and gut adhesions. In a prospective trial involving 22 patients with locally advanced pancreatic cancer, cryothermal ablation was applied to 16 patients among a cohort of 22 [42]. On followup CT scan, only 6 patients had clearly defined post tumor ablation margins, smaller compared to the initial mass. Mild complications were detected early, including abdominal pain with increased amylase levels and mild duodenal bleeding [42]. Limitations of this study included a small sample size and difficulty in determining the size of the ablated zone by CT scan. Furthermore, much of what is known about cryothermal ablation has been derived from animal studies, which cannot be generalized or extrapolated to humans. Large human studies are needed to determine the role, efficacy and safety of cryothermal ablation of pancreatic cysts given its potential benefits and safety profile.

\section{Laser ablation}

The use of neodymium: yttrium aluminum as an ablative agent has been used in the management of HCC. Laser ablation with neodymium: yttrium aluminum (Nd: YAG) emits light with a wavelength in the infrared spectrum at an energy output sufficient for the induction of tissue necrosis. A prospective animal study by Di Matteo et al, using a porcine model, assessed the feasibility of EUS-guided laser ablation of normal pancreatic tissue with an Nd: YAG laser [43]. Localized tissue necrosis was achieved in the pancreatic parenchyma. While the results are noteworthy, human studies are needed to validate and confirm these findings.

\section{Drug eluting ablation}

Karaca et al demonstrated the feasibility and safety of EUS-guided drug-eluting loaded beads in a porcine model. Drug depot with only localized pancreatic tissue reactions was observed on histopathology review. The authors concluded that EUS-guided injection of eluting drug beads into the pancreas was feasible and safe [44]. As with the Nd: YAH laser therapy 
experiments, outcomes and long-term effects on humans are unknown.

\section{Concluding remarks}

There is a need for future studies to determine the short- and long-term safety of EUS-guided cyst ablation. Future research is needed to determine whether cyst resolution leads to control of disease progression and tumor regression, and an improvement in quality of life and mortality. Additionally, it is unclear from these studies whether endoscopic cyst ablation leads to lower rates of infectious complications compared with surgery. A consensus is required as to whether EUS-guided cyst ablation is preferable in patients with a resectable disease who refuse surgery, or in patients with severe comorbidities that preclude curative surgery.

In conclusion, EUS cyst ablation is a potential alternative to surgical intervention. Several studies have documented much progress in developing alternative ablative methods. However, there are significant limitations that underscore these approaches and prevent their adoption in clinical practice. As noted earlier, many of these studies were conducted using porcine models and small sample sizes. Ethanol, chemotherapy, RFA and cryothermal ablative methods have been successfully used in human subjects, whereas other methods are limited to animal models. However, all these methods are experimental and should be used only within the confines of research protocols. Future research and clinical trials enrolling large human cohorts with longer follow-up times are required to determine their role in the management of pancreatic cysts. A head-to-head comparison of all four major techniques may also help develop therapeutic algorithms. For now, EUS-guided pancreatic cyst ablation should be considered experimental.

\section{References}

1. Yoon WJ, Brugge WR. Pancreatic cystic neoplasms: diagnosis and management. Gastroenterol Clin North Am 2012;41:103-118.

2. Scheiman JM, Hwang JH, Moayyedi P. American gastroenterological association technical review on the diagnosis and management of asymptomatic neoplastic pancreatic cysts. Gastroenterology 2015;148:824-848.e22.

3. Elta GH, Enestvedt BK, Sauer BG, Lennon AM. ACG Clinical Guideline: diagnosis and management of pancreatic cysts. Am J Gastroenterol 2018;113:464-479.

4. Moayyedi P, Weinberg DS, Schünemann H, Chak A. Management of pancreatic cysts in an evidence-based world. Gastroenterology 2015;148:692-695.

5. Arshad HM, Bharmal S, Duman DG, Liangpunsakul S, Turner BG. Advanced endoscopic ultrasound management techniques for preneoplastic pancreatic cystic lesions. J Investig Med 2017;65:7-14.

6. Paik WH, Lee SH, Jang S. Future perspectives on endoscopic ultrasonography-guided therapy for pancreatic neoplasm. Clin Endosc 2018;51:229-234.

7. GomezGómez V, Takahashi N, Levy MJ, et al. EUS-guided ethanol lavage does not reliably ablate pancreatic cystic neoplasms (with video). Gastrointest Endosc 2016;83:914-920.

8. Gelczer RK, Charboneau JW, Hussain S, Brown DL. Complications of percutaneous ethanol ablation. J Ultrasound Med 1998;17:531-533.

9. Brugge WR. Management and outcomes of pancreatic cystic lesions. Dig Liver Dis 2008;40:854-859.

10. GunterGünter E, Lingenfelser T, Eitelbach F, Müller H, Ell C. EUSguided ethanol injection for treatment of a GI stromal tumor. Gastrointest Endosc 2003;57:113-115.

11. Barclay RL, Perez-Miranda M, Giovannini M. EUS-guided treatment of a solid hepatic metastasis. Gastrointest Endosc 2002;55:266-270.

12. DeWitt J, Mohamadnejad M. EUS-guided alcohol ablation of metastatic pelvic lymph nodes after endoscopic resection of polypoid rectal cancer: the need for long-term surveillance. Gastrointest Endosc 2011;74:446-447.

13. DeWitt J. Endoscopic ultrasound-guided pancreatic cyst ablation. Gastrointest Endosc Clin N Am 2012;22:291-302.

14. Gan SI, Thompson CC, Lauwers GY, Bounds BC, Brugge WR. Ethanol lavage of pancreatic cystic lesions: initial pilot study. Gastrointest Endosc 2005;61:746-752.

15. DeWitt J, McGreevy K, Schmidt CM, Brugge WR. EUSguided ethanol versus saline solution lavage for pancreatic cysts: a randomized, double-blind study. Gastrointest Endosc 2009;70:710-723.

16. Park JK, Song BJ, Ryu JK, et al. Clinical outcomes of endoscopic ultrasonography-guided pancreatic cyst ablation. Pancreas 2016; 45:889-894.

17. DiMaio CJ, DeWitt JM, Brugge WR. Ablation of pancreatic cystic lesions: the use of multiple endoscopic ultrasound-guided ethanol lavage sessions. Pancreas 2011;40:664-668.

18. Choi JH, Lee SH, Choi YH, et al. Clinical outcomes of endoscopic ultrasound-guided ethanol ablation for pancreatic cystic lesions compared with the natural course: a propensity score matching analysis. Therap Adv Gastroenterol 2018;11:1756284818759929.

19. Moyer MT, Dye CE, Sharzehi S, et al. Is alcohol required for effective pancreatic cyst ablation? The prospective randomized CHARM trial pilot study. Endosc Int Open 2016;4:E603-E607.

20. Paiella S, Salvia R, Ramera M, et al. Local ablative strategies for ductal pancreatic cancer (radiofrequency ablation, irreversible electroporation): a review. Gastroenterol Res Pract 2016;2016:4508376.

21. Spechler SJ, Souza RF. Barrett's esophagus. N Engl J Med 2014; 371:836-845.

22. European Organisation For Research And Treatment Of Cancer. EASL-EORTC clinical practice guidelines: management of hepatocellular carcinoma. J Hepatol 2012;56:908-943.

23. LaquiereLaquière $A$, Boustière $C$, Leblanc $S$, Penaranda G, Désilets E, Prat F. Safety and feasibility of endoscopic biliary radiofrequency ablation treatment of extrahepatic cholangiocarcinoma. Surg Endosc 2016;30:1242-1248.

24. Lakhtakia S, Seo DW. Endoscopic ultrasonography-guided tumor ablation. Dig Endosc 2017;29:486-494.

25. Haen SP, Pereira PL, Salih HR, Rammensee HG, Gouttefangeas C. More than just tumor destruction: immunomodulation by thermal ablation of cancer. Clin Dev Immunol 2011;2011:160250.

26. Gaidhane M, Smith I, Ellen K, et al. Endoscopic ultrasound-guided radiofrequency ablation (EUS-RFA) of the pancreas in a porcine model. Gastroenterol Res Pract 2012;2012: 431-451.

27. Silviu UB, Daniel P, Claudiu M, et al. Endoscopic ultrasound-guided radiofrequency ablation of the pancreas: An experimental study with pathological correlation. Endosc Ultrasound 2015;4:330-335.

28. Wang D, Jin Z, Lei W, Leung JW, Li Z. Endoscopic ultrasound guided radiofrequency ablation for the treatment of advanced pancreatic carcinoma. Gastrointest Endosc 2013;77:AB414.

29. Song TJ, Seo DW, Lakhtakia S, et al. Initial experience of EUSguided radiofrequency ablation of unresectable pancreatic cancer. 
Gastrointest Endosc 2016;83:440-443.

30. Pai M, Habib N, Senturk H, et al. Endoscopic ultrasound guided radiofrequency ablation, for pancreatic cystic neoplasms and neuroendocrine tumors. World J Gastrointest Surg 2015;7:52-59.

31. Spiliotis JD, Datsis AC, Michalopoulos NV, et al. High operative risk of cool-tip radiofrequency ablation for unresectable pancreatic head cancer. J Surg Oncol 2007;96:89-90.

32. Matsui Y, Nakagawa A, Kamiyama Y, Yamamoto K, Kubo N, Nakase Y. Selective thermocoagulation of unresectable pancreatic cancers by using radiofrequency capacitive heating. Pancreas 2000;20:14-20.

33. Wright AS, Sampson LA, Warner TF, Mahvi DM, Lee FT Jr. Radiofrequency versus microwave ablation in a hepatic porcine model. Radiology 2005;236:132-139.

34. A phase II multicentre trial of endoscopic ultrasound guided radiofrequency ablation of cystic tumours of the pancreas. Available from: https://clinicaltrials.gov/ct2/show/NCT02343692 [Accessed November 21, 2018].

35. Rowinsky EK, Donehower RC. Paclitaxel (taxol). N Engl J Med 1995;332:1004-1014.

36. Oh HC, Seo DW, Lee TY, et al. New treatment for cystic tumors of the pancreas: EUS-guided ethanol lavage with paclitaxel injection. Gastrointest Endosc 2008;67:636-642.

37. Oh HC, Seo DW, Song TJ, et al. Endoscopic ultrasonographyguided ethanol lavage with paclitaxel injection treats patients with pancreatic cysts. Gastroenterology 2011;140:172-179.
38. Moyer MT, Sharzehi S, Mathew A, et al. The safety and efficacy of an alcohol-free pancreatic cyst ablation protocol. Gastroenterology 2017;153:1295-1303.

39. Signoretti M, Valente R, Repici A, Delle Fave G, Capurso G, Carrara S. Endoscopy-guided ablation of pancreatic lesions: Technical possibilities and clinical outlook. World J Gastrointest Endosc 2017;9:41-54.

40. Hines-Peralta A, Hollander CY, Solazzo S, Horkan C, Liu ZJ, Goldberg SN. Hybrid radiofrequency and cryoablation device: preliminary results in an animal model. J Vasc Interv Radiol 2004;15:1111-1120.

41. Carrara S, Arcidiacono PG, Albarello L, et al. Endoscopic ultrasound-guided application of a new hybrid cryotherm probe in porcine pancreas: a preliminary study. Endoscopy 2008;40:321-326.

42. Arcidiacono PG, Carrara S, Reni M, et al. Feasibility and safety of EUS-guided cryothermal ablation in patients with locally advanced pancreatic cancer. Gastrointest Endosc 2012;76:1142-1151.

43. Di Matteo F, Grasso R, Pacella CM, et al. EUS-guided Nd: YAG laser ablation of a hepatocellular carcinoma in the caudate lobe. Gastrointest Endosc 2011;73:632-636.

44. Karaca C, Cizginer S, Konuk Y, et al. Feasibility of EUS-guided injection of irinotecan-loaded microspheres into the swine pancreas. Gastrointest Endosc 2011;73:603-606.

45. Oh HC, Seo DW, Kim SC, et al. Septated cystic tumors of the pancreas: is it possible to treat them by endoscopic ultrasonographyguided intervention? Scand J Gastroenterol 2009;44:242-247. 